\title{
Maor, E. (2018). La música y los números. De Pitágoras a Schoenberg. Madrid: Turner, 182 pp. ISBN: 978-84-17141-73-8
}

La música y sus dimensiones fisicomatemáticas han sido temas recurrentes por parte de los teóricos a lo largo de los siglos. Incluso, como parte de los intentos por establecer una definición de la propia disciplina artística, la mayoría de las proposiciones presentan en común un elemento: el reconocimiento al número. Esto se debe a que cada sonido muestra un orden proporcional matemático, tanto en el aspecto armónico -relativo a las formaciones de escalas, intervalos o series armónicas- como en su concepción temporal -la duración-. Del mismo modo, la acústica está plagada de fórmulas matemáticas que permiten entender, desde una perspectiva científica, la formación de los elementos que participan en la creación sonora, como el funcionamiento de las ondas, los principios de difusión, reflexión y absorción de sonidos, la concepción de la acústica arquitectónica, la electroacústica, etc.

Aunque ya en la Antigüedad se reconoció la relevancia del número como parte esencial de la disciplina musical, lo cierto es que no son muchos los trabajos que aborden esta temática en la actualidad, momento en que disfrutamos de una gran proliferación de líneas temáticas diferentes. De acuerdo con este contexto, queremos presentar la edición española de La música y los números. De Pitágoras a Schoenberg, publicada en el año 2018 por Turner. Eli Maor, experto en historia de las matemáticas, es el autor de este ensayo, traducido por Inmaculada Pérez Parra, de amena lectura, que permite a los músicos adentrarse en el mundo de las matemáticas de la mano de la manifestación sonora, de la misma forma que anima a que los matemáticos puedan comprender la concepción interna del arte musical.

Tras el prefacio, repleto de vivencias personales que marcaron la vida y trayectoria personal del autor, se presentan doce breves capítulos que plantean un recorrido histórico sobre la relación existente entre la música y la ciencia matemática. Si bien "I. Prólogo" plantea una revisión teórica de carácter general sobre la física y la música de forma análoga, el segundo capítulo, "La teoría de cuerdas, 500 a.C.", presenta el intento de Pitágoras de dividir la octava en fragmentos más pequeños y musicalmente satisfactorios, esbozando cuestiones sobre las frecuencias y la armonía, mientras el tercer capítulo, "La Ilustración", profundiza en las principales leyes físicas sobre la vibración de los cuerpos. Por su parte, el capítulo IV, "El gran debate de las cuerdas, 1730-1780", incide en la relación cuantitativa entre la longitud de una cuerda y el tono de su sonido, así como en la discusión en torno a la cuerda pulsada protagonizado por Bernoulli, Euler, le Rond D’Alembert y Lagrange. El capítulo V, "Un don muy preciado", profundiza en torno a los tonos, los sonidos, el perfil de la onda y otros descubrimientos de Fourier y Helmholtz, mientras el sexto capítulo va dedicado al "Temperamento musical", planteando una revisión histórica desde la 
Antigüedad hasta el siglo XX, pasando por la Edad Media y el siglo XVIII, fecha especialmente destacada en torno al legado de Bach.

En el séptimo capítulo, “Artefactos musicales. El diapasón y el metrónomo”, se presenta el debate aún existente sobre la afinación en torno al diapasón, este artilugio que presenta la marca estándar de frecuencia, y hace lo propio también en torno al metrónomo, presentando la evolución musical y los argumentos en torno a este instrumento fundamental en la duración del tiempo. Por su parte, en el octavo capítulo, "Ritmo, compás y métrica", se profundiza en la perfección matemática de la música a partir de Bach, Mussorgsky y Stravinsky, mientras “IX. Marcos de referencia. ¿Dónde estoy?” plantea la aplicación de la geometría a las artes, comenzando con la incidencia de la perspectiva en la pintura y continuando, para una mayor ampliación, con los intervalos de las escalas y los grados de las tonalidades.

Posteriormente, tras el carácter histórico general planteado hasta el momento, Maor personifica la relación música-matemática en torno a dos figuras que presentan numerosas coincidencias en su vida y en su legado, como Schoenberg y Einstein. Así, en el capítulo X, "Música relativa", Maor, a partir de sus profundos conocimientos, plantea una reflexión que resultará, sin duda, resultará evocadora para el lector- sobre si la teoría de la relatividad de Einstein pudo influir en la música de Schoenberg, mientras que la repercusión de las ideas revolucionarias de ambos teóricos se presenta en "XI. Repercusión". Por último, el capítulo XII", "Los últimos pitagóricos", donde no solo se recupera la teoría de las esferas en torno a los nuevos descubrimientos planetarios y las nuevas líneas de investigación sobre la cosmología, sino que se abre la puerta a nuevos trabajos para los matemáticos del futuro.

El volumen, que finaliza con una variada bibliografía igualmente musical que matemática, significa un alarde de conocimiento técnico por parte del autor, pero también demuestra el valor de la divulgación científica en torno a la interdisciplinariedad de dos ciencias aparentemente tan dispares pero que están intrínsecamente relacionadas en torno a la disciplina musical. No hay duda de que este vestigio bibliográfico, cuya lectura es altamente recomendable, resultará de gran interés y utilidad para todos aquellos músicos, matemáticos y lectores interesados en una mirada científica hacia las artes y en una visión artística de los acontecimientos científicos del pasado.

\section{Virginia Sánchez Rodríguez}

Universidad de Castilla-La Mancha

Centro de Investigación y Documentación Musical (CIDoM)-Unidad Asociada al CSIC

ORCID iD: https://orcid.org/0000-0001-8071-2937 